\title{
Artikel
}

\section{Access to Justice voor 12- tot 16-jarigen bij niet-nakoming van de geneeskundige behandelingsovereenkomst?}

\author{
B. Blanckenburg LL.M, I.F.H.M. Gerrits LL.B en dr. M.P. Sombroek-van Doorm*
}

\section{Inleiding}

Bij de totstandkoming van de Wet op de Geneeskundige Behandelingsovereenkomst (WGBO) heeft de wetgever gekozen voor het invoeren van leeftijdscategorieën om de rechtspositie tussen de gezagdragende ouders (hierna: 'de ouders'), het kind en de arts te regelen. ${ }^{1}$ Afhankelijk van de leeftijd van het kind zijn ouders (mede) beslissingsbevoegd ten aanzien van het al dan niet geven van toestemming voor de geneeskundige behandeling van hun kind. Uit de WGBO volgt immers dat wanneer de geneeskundige behandeling betrekking heeft op kinderen jonger dan 12 jaar, de ouders toestemming dienen te verlenen voor de uitvoering van die behandeling. Gaat het om jeugdigen in de leeftijdscategorie van 12 tot 16 jaar, dan is in beginsel zowel de toestemming van de ouders alsook die van de jeugdige zelf nodig.

In beginsel, omdat in het geval dat ouders geen toestemming verlenen en dit 'niet-verlenen' ernstig nadeel voor de jeugdige patiënt tussen de 12 en 16 jaar zou opleveren, of indien die jeugdige, ondanks het ontbreken van de toestemming van zijn of haar ouders, de

B. Blanckenburg LL.M is advocaat bij Van Doorn cs advocaten. I.F.H.M Gerrits LL.B is masterstudent jeugdrecht aan de Universiteit van Leiden. Dr. M.P. Sombroek-van Doorm is directeur van de Faculteit der Rechtsgeleerdheid en benoemd in het Faculteitsbestuur. Verder is zij universitair docent bij de afdeling jeugdrecht en tuchtrechter bij het Regionaal Tuchtcollege voor de gezondheidszorg in Amsterdam.

1. Kamerstukken I/ 1989/90, 21561, nr. 3, p. 19-21 behandeling weloverwogen blijft wensen, de arts, als goed hulpverlener, kan beslissen om aan de vereiste toestemming van de ouders voorbij te gaan. ${ }^{2}$ De toestemming voor behandeling van de jeugdige is dan voldoende. Is de jeugdige eenmaal 16 jaar of ouder, dan is hij of zij volgens de wetgever capabel genoeg zelfstandig te beslissen over het al dan niet aangaan van een geneeskundige behandelingsovereenkomst. Toestemming van ouders is dan niet langer aan de orde. Deze leeftijdscategorieën in de WGBO verduidelijken hoe de wetgever - in een medische context - denkt over de invulling van de evolving capacities van het kind, zoals genoemd in artikel 5 van het Internationaal Verdrag inzake de Rechten van het Kind (IVRK).

De materiële bekwaamheid van jeugdigen vanaf 12 jaar, die de WGBO met betrekking tot het aangaan van een geneeskundige behandelingsovereenkomst hanteert, loopt evenwel (nog) niet in de pas met de processuele bekwaamheid van de groep jeugdigen tussen 12 en 16 jaar. De WGBO kent immers alleen voor de jeugdigen van 16 en 17 jaar een regeling die de oudere minderjarigen bekwaam maakt zelfstandig in een procedure, en ook buiten rechte, hun belangen te behartigen. ${ }^{3}$ Voor jeugdigen van 12 tot 16 jaar bestaat een dergelijke regeling vooralsnog niet. Dit betekent dus dat zij geen zelfstandige toegang hebben tot de rechter in geval van niet-nakoming van de geneeskundige behandelingsovereenkomst. Dat, terwijl die behandeling wel op grond van hun toestemming kan plaatsvinden. Immers, als de ouders toestemming weigeren, kan de arts daaraan op 
grond van zijn goed hulpverlenerschap voorbijgaan en kan de behandeling worden uitgevoerd.

De wetgever heeft de verantwoordelijkheid voor het voeren van een gerechtelijke procedure bij niet-nakoming van de geneeskundige behandelingsovereenkomst die betrekking heeft op een minderjarige jonger dan 16 jaar in eerste instantie bij de ouders neergelegd. Uiteraard valt dit te verklaren vanuit de verantwoordelijkheid die ouders hebben voor de opvoeding en verzorging van het kind. ${ }^{4}$ Maar ingeval er sprake is van een conflict tussen ouders en kind, en de ouders niet in rechte willen optreden voor hun kind, dan rijst de vraag in hoeverre Access to Fustice via de informele rechtsingang van artikel 1:250 BW wordt geborgd. ${ }^{5}$ Deze regeling voorziet weliswaar in de mogelijkheid dat de rechter in conflicten van substantiële aard tussen ouders en kind een bijzondere curator kan benoemen om de belangen van de jeugdige te behartigen, maar houdt niet in dat de jeugdige tussen de 12 en 16 jaar een zelfstandige toegang tot de rechter toekomt in geval van nietnakoming van de behandelingsovereenkomst.

In dit artikel gaan auteurs in op het recht op Access to Fustice vanuit mensenrechten en kinderrechtenperspectief. Hierbij gaat het bovenal om de situatie waarin sprake is van een materiële bekwaamheid van kinderen tussen de 12 en 16 jaar om te kiezen voor een geneeskundige behandeling zonder daarvoor toestemming te hebben van de ouders. Bijzondere aandacht gaat uit naar de rol van leeftijdsgrenzen bij het bepalen van die bekwaamheid en de processuele onbekwaamheid om zelfstandig in een procedure zijn/haar belangen te behartigen. In hoeverre de processuele bekwaamheid van de minderjarige patiënt meer in lijn kan worden gebracht met de materiële bekwaamheid van die patiënt onder de WGBO komt aan de orde in de afsluiting van dit artikel.

\section{Access to Justice vanuit mensenrechtenperspectief}

Het recht op Access to Fustice is terug te vinden in artikel 6 lid 1 van het Europees Verdrag voor de Rechten van de Mens (EVRM). Het recht op toegang tot de rechter is inherent aan het recht op een eerlijk proces. ${ }^{6}$ Het beginsel dat een civiele vordering bij de rechter moet kunnen worden ingediend, is volgens het Europees Hof een van de universeel erkende fundamentele rechtsbeginselen. ${ }^{7}$ Daarnaast dient Access to Fustice daadwerkelijk en effectief te zijn, waarbij het individu dient te beschikken over 'a clear, practical opportunity to chal-

Art. 1:247 lid 1 en 2 BW.

Art. 7:450 jo. 1:245 lid 4 BW.

. European Court of Human Rights, Guide on Article 6 of the Convention - Right to a fair trial (civil limb), 31 August 2019, par. 84-86; ECtHR 21 February 1975, Application no. 4451/70, par. 36 (Golder v. The United Kingdom)

7. ECtHR 21 February 1975, Application no. 4451/70, par. 34-36 (Golder v. The United Kingdom). lenge an act that is an interference with his rights' ${ }^{8}$ Tegelijkertijd vormt toegang tot de rechter geen absoluut recht. Beperkingen ervan zijn mogelijk, al mag dit er niet toe leiden dat de essentie van het recht wordt aangetast. ${ }^{9}$ Het Hof benadrukt verder dat een beperking van dit mensenrecht zonder legitiem doel, waarbij de ingezette middelen ook niet evenredig in verhouding staan tot het beoogde doel, niet verenigbaar is met artikel 6 lid 1 EVRM. ${ }^{10}$

Ook internationale kinderrechten kunnen worden beschouwd als mensenrechten en fundamentele vrijheden, aldus - onder meer - Kilkelly en Liefaard. ${ }^{11}$ Andersom geldt dit ook.

Kinderen worden mede onder invloed van het IVRK gezien als zelfstandige dragers van rechten. Wat betreft de uitoefening van hun rechten zal uiteraard telkenmale de vraag moeten worden gesteld in hoeverre kinderen ook daadwerkelijk in staat zijn tot een redelijke waardering van hun belangen ter zake. Op het moment dat een behandeling zonder toestemming van de ouders wordt uitgevoerd, omdat het kind deze weloverwogen blijft wensen en ouders niet instemmen, dan beschikt de jeugdige kennelijk over het noodzakelijke inzicht om rechtshandelingen te verrichten ter zake van de geneeskundige behandelingsovereenkomst, evenals de 16- en 17-jarige. Waarom geldt dan niet voor de groep jeugdige patiënten tussen de 12 en 16 jaar eenzelfde regeling als artikel 7:447 lid $3 \mathrm{BW}$, zodat het recht op Access to Fustice is gegarandeerd?

Over het belang van een toegang tot de rechter voor kinderen wordt in de Guidelines on Child-friendly Fustice van de Raad van Europa, die zijn voortgekomen uit de rechtspraak van het EHRM over de toepassing van het EVRM en het IVRK, het volgende benadrukt: ${ }^{12}$

'It is, in particular, justice that is accessible, age appropriate, speedy, diligent, adapted to and focused on the needs and rights of the child, respecting the rights of the child including the rights to due process, to participate in and to understand the proceedings, to respect for private and family life and to integrity and dignity.' 13

8. European Court of Human Rights, Guide on Article 6 of the Convention - Right to a fair trial (civil limb), 31 August 2019, par. 91; ECtHR 4 December 1995, Application no. 23805/94, par. 36-38 (Bellet v. France).

9. European Court of Human Rights, Guide on Article 6 of the Convention - Right to a fair trial (civil limb), 31 August 2019, par. 87.

10. European Court of Human Rights, Guide on Article 6 of the Convention - Right to a fair trial (civil limb), 31 August 2019, par. 87.

11. U. Kilkelly \& T. Liefaard, 'International Children's Rights: Reflections on a Complex, Dynamic, and Relativeley Young Area of Law, in: U. Kilkelly \& T. Liefaard (red.), International Human Rights of Children, Singapore: Springer Nature 2019, p. 617-627.

12. Committee of Ministers of the Council of Europe, Guidelines on Childfriendly justice, Explanatory memorandum, 17 November 2010, par. 21, 25 and 32; T. Liefaard \& S. Rap, 'Hoezo kindvriendelijk? Over 'child-friendly justice' ter bevordering van effectieve participatie van kinderen in juridische procedures en besluitvorming', FJR 2018 (6), p. 180.

13. Committee of Ministers of the Council of Europe, Guidelines on Childfriendly justice, 17 November 2010, Chapter II par. c. 
Uiteraard is het aan lidstaten gelaten om hier nader invulling aan te geven en te bepalen wat 'age appropriate' betekent en hoe zij de rechtsingang voor minderjarigen vormgeven. Daartoe staan verschillende opties open. Zo is het mogelijk om kinderen direct toegang tot de rechter te verlenen via een eigen rechtsingang, alsook om de toegang indirect, via de ouders, via een bijzondere curator of jeugdadvocaat te laten verlopen; zolang de toegang tot de rechter maar effectief geborgd is. Hieruit volgt dus niet zonder meer een zelfstandige rechtsingang voor minderjarigen. Maar deze wordt ook niet uitgesloten. ${ }^{14}$

Hoe in de lidstaten de vormgeving van toegang tot de rechter kan verschillen blijkt wel als het Nederlandse systeem met ons buurland België wordt vergeleken. België kent een uitzondering op de algemene regel met betrekking tot de processuele onbekwaamheid van minderjarigen, waardoor een minderjarige, dus ook die tussen de 12-16 jaar, toch een procedure kan inleiden bij de rechtbank..$^{15}$ Ofschoon dit vanuit het oogpunt van Access to Fustice een welkome gedachte is, angezien het de minderjarige bekwaam maakt zelfstandig een procedure te starten en zijn belangen te behartigen, is er ook een schaduwzijde. De verweerder kan alsnog een beroep doen op de niet-vertegenwoordiging van de minderjarige, waardoor de zaak niet-ontvankelijk kan worden verklaard. ${ }^{16}$ Ofschoon dit kan worden verholpen door de ouders alsnog in het geding te brengen, biedt dit de jeugdige geen soelaas als er sprake is van een conflict tussen ouders en de jeugdige. ${ }^{17}$ Wanneer er sprake is van tegenstrijdige belangen tussen de ouders en de jeugdige, kunnen belanghebbenden de rechter op grond van artikel 378 paragraaf 1 Belgisch BW verzoeken een voogd ad hoc aan de minderjarige toe te wijzen of kan de rechter hier ambtshalve zelf het initiatief toe nemen. Van een ongeclausuleerde zelfstandige rechtsingang voor de minderjarige is dus geen sprake. Daarom is de Belgische Senaat al enige jaren bezig met het invoeren van een specifiek recht voor minderjarigen op toegang tot de rechter. ${ }^{18}$

Kennelijk is - ingeval het recht op een goede behandeling is geschonden waarvoor de minderjarige tussen de 12 en 16 jaar toestemming heeft gegeven maar de ouders niet - meer aandacht nodig voor het waarborgen van Access to Fustice voor die specifieke groep in die specifieke situatie.

14. T. Liefaard, 'Access to Justice for Children: Towards a Specific Research and Implementation Agenda', The International Journal of Children's Rights, 2019, p. 105-227.

15. Belgische Senaat $2010 / 11,5-604 / 1$, p. 1 en 2

16. Belgische Senaat $2010 / 11,5-604 / 1$, p. 1 en 2

17. Belgische Senaat $2010 / 11,5-604 / 1$, p. 1 en 2.

18. Belgische Senaat $2001 / 02,2-626 / 5$, p. 20; Belgische Senaat 2006/07, 4-126/1, p. 5; Belgische Senaat 2010/11, 5-604/1, p. 10.

\section{Access to Justice voor minderjarigen vanuit kinderrechtenperspectief}

Het IVRK bevat geen expliciete bepaling waarin het recht op Access to fustice voor minderjarigen is geregeld. ${ }^{19}$ In General Comment nr. 5 geeft het VN-Kinderrechtencomité evenwel aan dat in algemene zin rechten pas betekenis krijgen wanneer er effectieve rechtsmiddelen openstaan om eventuele inbreuken op die rechten te kunnen herstellen. ${ }^{20}$ Hierbij wijst het Comité erop dat het voor kinderen, vanwege hun afhankelijke positie, moeilijk kan zijn om een doeltreffende oplossing te vinden indien er een schending van hun rechten heeft plaatsgevonden. ${ }^{21} \mathrm{Om}$ deze reden benadrukt het VNKinderrechtencomité dan ook dat Staten er alert op moeten zijn dat er voor kinderen effectieve kindvriendelijke procedures zijn. Daarvoor is nodig dat an kinderen voor het kind begrijpelijke informatie en advies wordt gegeven, er sprake is van begeleiding en belangenbehartiging en voorts toegang tot onafhankelijke klachtenprocedures en rechtbanken, met de nodige (juridische) bijstand. ${ }^{22}$ Patiënten tussen de 12 en 16 jaar zijn vanwege hun processuele onbekwaamheid bij nietnakoming van de geneeskundige behandelingsovereenkomst voor toegang tot de rechter in eerste instantie aangewezen op hun ouders, ook in die situaties waarin er sprake is van een behandeling waarvoor de ouders geen toestemming hebben verleend. ${ }^{23}$ Kennelijk heeft de wetgever in de geneeskundige context de evolving capacities (art. 5 IVRK) anders ingekleurd dan in de context van het voeren van een gerechtelijke procedure - ook al is die te herleiden tot die geneeskundige context.

Het uitgangspunt van de wetgever is dat het de taak en verantwoordelijkheid van de ouders is om hun kind in procedures te vertegenwoordigen en te ondersteunen. Niettemin hoeft het weinig betoog dat dit ingewikkeld is, laat staan effectief, als kind en ouders niet op dezelfde lijn zitten. Indien ouders niet instemmen met een geneeskundige behandeling, is het nog maar de vraag of die ouders het kind wel in rechte millen vertegenwoordigen. Nog even daargelaten of zij - als zij hun

19. Zie HR 5 december 2014, ECLI:NL:2014:3535. De Hoge Raad leest in art. 12 IVRK het recht op toegang tot de rechter voor de minderjarige.

20. UN Committee on the Rights of the Child, General comment No. 5 (2003): General measures of implementation of the Convention on the Rights of the Child (arts. 4, 42 and 44, para. 6), 27 November 2005, CRC/GC/2003/5, par. 24. Zie ook: T. Liefaard, 'Access to Justice for Children: Towards a Specific Research and Implementation Agenda', The International Journal of Children's Rights, 2019, p. 105-227.

21. UN Committee on the Rights of the Child, General comment No. 5 (2003): General measures of implementation of the Convention on the Rights of the Child (arts. 4, 42 and 44, para. 6), 27 November 2005, CRC/GC/2003/5, par. 24.

22. UN Committee on the Rights of the Child, General comment No. 5 (2003): General measures of implementation of the Convention on the Rights of the Child (arts. 4, 42 and 44, para. 6), 27 November 2005, CRC/GC/2003/5, par. 24.

23. Art. 7:450 jo. 1:245 lid 4 BW. 
kind wel vertegenwoordigen - diens belangen ook voldoende kunnen en willen behartigen. Indien de ouders gedurende de procedure bijvoorbeeld tot een schikking met de arts komen waar het kind niet achter staat, welke weg staat er dan voor het kind nog open? Uiteraard biedt artikel 1:250 BW de mogelijkheid om een bijzondere curator aan het kind toe te wijzen als er sprake is van een belangenstrijd tussen ouders en kind. ${ }^{24}$ Het moet dan wel gaan om een wezenlijk conflict over de verzorging of opvoeding, dan wel het vermogen van het kind. ${ }^{25}$ Het komt ons voor dat hiervan sprake is als ouders en kind van mening verschillen over het al dan niet uitvoeren van een behandelingsovereenkomst. Bij niet-nakoming van de behandelingsovereenkomsten kan deze informele rechtsingang voor de jeugdige weliswaar een uitkomst bieden, maar de jeugdige tussen de 12 en 16 jaar heeft in de gerechtelijke procedure dan nog steeds niet, zoals dat wel het geval is bij de uitoefening van het toestemmingsrecht, eenzelfde rechtspositie als die van 16 en 17-jarigen. De jeugdige blijft afhankelijk van bereidwillige ouders die de gang naar de rechter maken of van de toewijzing van een bijzondere curator die er vervolgens zelf van overtuigd moet zijn dat het voeren van een gerechtelijke procedure in het belang van de jeugdige is. De vraag rijst of de jeugdige tussen de 12 en 16 jaar die zelfstandig toestemming heeft gegeven voor een geneeskundige behandeling op deze wijze wel voldoende rechtsbescherming toekomt. Deze vraag is des te relevanter nu uit onderzoek blijkt dat de mogelijkheid tot een zelfstandige rechtsingang voor jeugdigen vanwege hun afhankelijkheidspositie nader dient te worden bezien. ${ }^{26}$ Het blijft op zijn zachtst gezegd onbevredigend dat daar waar de WGBO wel in specifieke situaties ruimte laat om alleen op basis van toestemming van de minderjarige tussen de 12 en 16 jaar over te gaan tot een geneeskundige behandeling, geen voorziening treft voor de nakoming ervan. Anders dan de 16- en 17jarige patiënten hebben zij niet een zelfstandige toegang tot de rechter, kunnen zij niet deelnemen aan de gerechtelijke procedure en hebben zij niet de mogelijkheid om waar gewenst zelfstandig in hoger beroep te gaan. De WGBO blijkt hier dus slechts deels in overeenstemming met de toelichting van het $\mathrm{VN}-\mathrm{Kinderrechtencomité.}$

24. Bij het benoemen van een bijzondere curator door de rechter werd vooral gedacht aan de positie van het kind in het kader van een echtscheidingsprocedure.

25. HR 4 februari 2005, ECLI:NL:HR:2005:AR4850, r.o. 3.4.1, 3.4.2 en 3.4.3; Kamerstukken I/ 1992/93, 23012, nr. 3, p. 11 en 12.

26. Staatscommissie Herijking Ouderschap, Kind en ouders in de 21e eeuw (2016), p. 11. Zie: HR 5 december 2014, ECLI:NL:HR:2014:3535. Volgens de Hoge Raad garandeert de mogelijkheid tot benoeming van een bijzondere curator het in art. 6 lid 1 EVRM en art. 12 IVRK verankerde recht op toegang tot de rechter, mits deze mogelijkheid effectief kan worden benut. Zie ook: Kinderombudsman, De bijzonder curator, een lot uit de loterij? (2012). Zie ook: M.R. Bruning, D.J.H. Smeets, K.G.A. Bolscher, J.S. Peper \& R. de Boer, Kind in proces: van communicatie naar effectieve participatie. Het hoorrecht en de procespositie van minderiarigen in familie- en jeugdzaken, 2012.

\section{Materieel bekwaam en processueel onbekwaam op basis van leeftijdsgrenzen?}

Waar kinderen vroeger vooral werden gezien als kwetsbare mensen die bescherming behoeven, worden zij tegenwoordig gezien als zelfstandige rechtssubjecten. Deze ontwikkeling is niet alleen zichtbaar in de uitgangspunten van het IVRK, maar ook in de toevoeging van het Derde Facultatief Protocol bij het IVRK in 2014. Wanneer kinderen van mening zijn dat hun rechten worden geschonden en alle rechtsmiddelen in het eigen land zijn uitgeput, kunnen zij immers via dit Derde Facultatief Protocol een klacht indienen bij het VNKinderrechtencomité. ${ }^{27}$ Dat kinderen worden gezien als zelfstandige rechtssubjecten, blijkt ook uit de toepassing van de WGBO in de dagelijkse praktijk. Minderjarige patiënten zijn samen met hun ouders in toenemende mate coauteur geworden van hun eigen behandeltraject. Waar de arts vroeger vanuit zijn medische kennis een vrij paternalistische rol innam, de behandelmogelijkheden overwoog, een besluit nam en dit communiceerde aan de patiënt, is de arts-patiëntrelatie sinds de opkomst van patiëntenrechten gelijkwaardiger geworden. De laatste jaren is in toenemende mate sprake van gezamenlijke besluitvorming. ${ }^{28}$ Daartoe verschaft de arts de minderjarige en zijn ouders informatie ten aanzien van de gezondheidstoestand van de minderjarige, de mogelijke behandelopties en de consequenties van deze behandelopties. Dat dient de arts op een zodanige wijze te doen dat ook de minderjarige deze informatie begrijpt. Dit stelt de jeugdige in staat geinformeerd toestemming te verlenen voor het uitvoeren van de geneeskundige behandeling. Dat geldt ook voor het beslissen welke geneeskundige behandeling de voorkeur verdient als meerdere behandelopties mogelijk zijn. ${ }^{29}$ In het licht

27. UN Committee on the Rights of the Child, Optional Protocol to the Convention on the Rights of the Child on a communications procedure, 14 April 2014, Part II article 5 and 7. Dat kinderen hierbij steeds vaker over de capaciteiten beschikken om zelf voor hun rechten op te komen, blijkt onder meer uit de klimaatklacht die op 23 september 2019 door 16 kinderen in de leeftijd van 8 tot 18 jaar werd ingediend bij het VNKinderrechtencomité tegen Argentinië, Brazilië, Duitsland, Frankrijk en Turkije. Landen die alle het Derde Facultatief Protocol hebben geratificeerd en, volgens de kinderen, onvoldoende maatregelen nemen om klimaatverandering tegen te gaan, waardoor zij van mening zijn dat het recht op leven (art. 6 IVRK), het recht op gezondheid (art. 24 IVRK), het recht op een eigen cultuur (art. 30 IVRK) en het belang van het kind als eerste overweging (art. 3 IVRK) wordt geschonden. Dergelijke acties, alsook de voor Nederland bekende casus van de 12-jarige David, die door de rechter wilsbekwaam werd geacht ten aanzien van het nemen van de beslissing om af te zien van een chemobehandeling die zijn kansen op herstel zou bevorderen, dragen bij aan de toenemende maatschappelijke erkenning van minderjarigen als zelfstandige rechtssubjecten.

28. Kamerstukken I/ 2017/18, 34994, nr. 3, p. 3-6. M. Ouwens, S. van der Burg, M. Faber \& T. Van der Weijden, Shared Decision Making \& Zelfmanagement, Nijmegen: Scientific Institute for Quality of Healtcare, UMC St. Radboud 2012, p. 31-33.

29. UN Committee on the Rights of the Child, General comment No. 12 (2009): The right of the child to be heard, 20 July 2009, CRC/C/GC/12, par. 25; Art. 7:448 lid 2 BW. 
van de huidige focus op 'patient-centered care' en 'shared decision-making' kan gesteld worden dat de WGBO-wetgever in 1995 zijn tijd dus al ver vooruit was met het invoeren van het toestemmingsrecht voor minderjarigen vanaf 12 jaar. ${ }^{30}$ Reden voor de wetgever om minderjarigen vanaf 12 jaar materieel bekwaam te achten ten aanzien van de uitoefening van het toestemmingsrecht is volgens de Memorie van Toelichting gelegen in de gedachte dat zij beschikken over het vermogen tot een redelijke waardering van hun belangen ter zake. ${ }^{31}$ In lijn met die gedachte en met inachtneming van de bescherming van minderjarigen jonger dan 12 jaar heeft de wetgever vervolgens in artikel 7:465 leden 1 en 2 BW, die zien op de nakoming van de geneeskundige behandelingsovereenkomst door de arts, het volgende bepaald. Wanneer een patiënt de leeftijd van 12 jaar heeft bereikt, maar niet in staat kan worden geacht tot een redelijke waardering van de eigen belangen, komt de arts de verplichtingen uit de geneeskundige behandelingsovereenkomst na jegens de ouders. ${ }^{32}$ Omgekeerd betekent dit dat wanneer een minderjarige van 12 tot 16 jaar wel over de capaciteiten beschikt om zijn/haar eigen belangen te waarderen, de arts jegens die jeugdige tot nakoming van de geneeskundige behandelingsovereenkomst gehouden is.

In dit licht is het, zoals hiervoor ook gezegd, bevreemdend dat als niet wordt nagekomen, de minderjarige patiënt niet bekwaam wordt geacht om in en buiten rechte op te treden en dat er geen uitzondering is geformuleerd zoals dat wel het geval is voor 16- en 17-jarigen. Waar de wetgever ervoor heeft gekozen om de discrepantie tussen de materiële bekwaamheid en processuele onbekwaamheid voor 16- en 17-jarigen op te heffen, vanuit de gedachte dat 16- en 17-jarigen beschikken over het noodzakelijke inzicht om rechtshandelingen te kunnen verrichten ter zake van de geneeskundige behandelingsovereenkomst, heeft de wetgever dit voor 12- tot 16-jarigen achterwege gelaten. ${ }^{33}$ Waarom is niet voor eenzelfde regeling gekozen voor de patiënten tussen de 12 en 16 jaar die zonder toestemming van ouders een behandeling kunnen en mogen ondergaan die zij weloverwogen blijven wensen of die ernstig nadeel voorkomt ${ }^{34}$ Het verlenen van toestemming voor zo'n geneeskundige behandeling is immers ook een rechtshandeling. Bovendien was de motivering bij het invoeren van het toestemmingsrecht voor minderjarigen vanaf 12 jaar juist dat minderjarigen vanaf 12 jaar over het vermogen beschikken tot een redelijke waardering van hun belangen. ${ }^{35}$ Steun voor de gedachte om de jeugdige tussen de 12 en 16 jaar zelf in rechte te laten optreden, omdat zij in staat zijn tot een redelijke waar-

30. Kamerstukken // 2017/18, 34994, nr. 3, p. 3-6.

31. Kamerstukken // 1989/90, 21561, nr. 3, p. 20 en 21

32. Art. 7:465 lid 1 en 2 BW.

33. Kamerstukken II 1989/90, 21561, nr. 3, p. 19; Kamerstukken II 1999/2000, 26862, nr. 6, p. 11.

34. Steun hiervoor kan worden gevonden in art. 8 lid 1 Awb waarin is bepaald dat 'onbekwamen' zelf in rechte mogen optreden 'indien zij tot een redelijke waardering van hun belangen in staat kunnen worden geacht'.

35. Kamerstukken // 1989/90, 21561, nr. 3, p. 20 en 21 dering van hun belangen, is eveneens te vinden in het jeugdrecht en het bestuursrecht. ${ }^{36}$

In dit licht en in samenhang met de visie van het $\mathrm{VN}$ Kinderrechtencomité dat kinderen in staat moeten worden gesteld om hun rechten zoveel mogelijk zelf uit te oefenen overeenkomstig hun evolving capacities, rijst de vraag of leeftijd wel de juiste grondslag is voor het bepalen van de procesbekwaamheid van minderjarigen. Uit de Memorie van Toelichting blijkt immers dat voor de vaststelling van de leeftijdscategorieën en de bijbehorende bekwaamheidsoordelen is gekeken naar 'het vermogen om een redelijke waardering van de eigen belangen te kunnen maken' en 'het noodzakelijke inzicht om rechtshandelingen te kunnen verrichten'. Dat laatste criterium heeft ertoe geleid dat 16- en 17-jarigen, naast materieel bekwaam, ook processueel bekwaam worden geacht. ${ }^{37}$ De vraag is echter in hoeverre deze twee criteria van elkaar verschillen en of zij onderaan de streep niet op hetzelfde neerkomen. Om rechtshandelingen te kunnen verrichten in het kader van de geneeskundige behandelingsovereenkomst is het immers noodzakelijk dat minderjarigen beschikken over een bepaald begripsvermogen, waardoor zij de informatie kunnen begrijpen, relevante belangen tegen elkaar af kunnen wegen en een weloverwogen beslissing kunnen maken. Dit begripsvermogen speelt een belangrijke rol bij zowel het besluit toestemming te verlenen voor een behandeling, alsook bij de beslissing om een geschil voor te leggen aan de rechter. Met andere woorden: vragen beide rechtshandelingen niet om soortgelijke capaciteiten van de jeugdige? Kan de regeling van artikel 7:450 lid 2 BW die de materiële bekwaamheid van minderjarigen tussen de 12 en 16 jaar weerspiegelt niet als grondslag gelden voor het introduceren van een formele rechtsingang voor minderjarigen in het burgerlijk recht? Steun voor die gedachte kan worden gevonden in het tuchtrecht. Naar de letter van de wet is het niet uitgesloten dat minderjarigen in de leeftijd van 12 tot 16 jaar zich tot de Tuchtcolleges voor de Gezondheidszorg (hierna:

36. Uitzonderingen op de processuele onbekwaamheid van minderjarigen in jeugdbeschermingszaken: minderjarigen vanaf 12 jaar, en ook minderjarigen jonger dan 12 jaar die in staat zijn een redelijke waardering van hun belangen ter zake te maken, kunnen bijvoorbeeld in procedures die zien op de toekenning van eenhoofdig gezag (art. 1:251a lid 4 BW), omgang en informatie (art. 1:377g BW) of de verdeling van zorg- en opvoedtaken (1:253a lid 4 BW) zich via een informele rechtsingang wenden tot de rechter. Hierbij hoeft de minderjarige zich niet te laten vertegenwoordigen door een gezagdragende ouder of bijzondere curator en kan de rechter ambtshalve op het verzoek van de minderjarige beslissen; HR 29 mei 2015, ECLI:NL:HR:2015:1409, r.o. 3.4.4. Ook beschikken minderjarigen van 12 jaar en ouder in het jeugdbeschermingsrecht in een aantal gevallen over een formele rechtsingang. Dit is onder meer het geval bij procedures inzake de ondertoezichtstelling en uithuisplaatsing (art. 1:259, 1:261 lid 2, 1:262b, 1:264 lid 1, 1:265 lid 1, 1:265d lid 2, 1:265g lid 2 BW), alsook bij zaken met betrekking tot een machtiging gesloten jeugdzorg (art. 6.1.1 lid 2 Jeugdwet). En ook: de uitzondering op de processuele onbekwaamheid van minderjarigen in het bestuursrecht, waarbij minderjarigen die in staat worden geacht een redelijke waardering van hun belangen ter zake te kunnen maken, zelf in het geding mogen optreden (art. 8:21 lid $2 \mathrm{Awb}$ ).

37. Kamerstukken II 1989/90, 21561, nr. 3, p. 19; Kamerstukken II 1999/2000, 26862, nr. 6, p. 11; Kamerstukken II 1989/90, 21561, nr. 3, p. 20 en 21 
Tuchtcolleges) kunnen wenden. ${ }^{38}$ Ofschoon die mogelijkheid nergens expliciet is geregeld, wordt zij ook nergens uitgesloten. Ingevolge de Wet BIG kan een klacht worden ingediend bij het Tuchtcollege door de 'rechtstreeks belanghebbende'. ${ }^{39}$ 'Rechtstreeks belanghebbende' kan hierbij betrekking hebben op de patiënt en op de ouders, waarbij de term 'patiënt' zowel een minderjarige als een volwassene kan betreffen en het benoemen van de 'ouder' als persoon die namens een minderjarige jonger dan 16 jaar een klacht in kan dienen, ook de minderjarige patiënt zelf niet uitsluit. Uitgangspunt is dat als de patiënt hiertoe behoorlijk in staat is, hij degene is die beslist over het indienen van een klacht. ${ }^{40}$ Kennelijk is het naar de letter van de wet wel mogelijk een tuchtrechtelijke procedure te starten, terwijl dit niet geldt voor het starten van een civielrechtelijke procedure als er sprake is van niet-nakoming van de geneeskundige behandelingsovereenkomst. Het is de vraag of dit onderscheid in toegang tot de tucht- en civielrechtelijke rechtspraak houdbaar is.

\section{Samenvatting en conclusie}

Access to Fustice is te herleiden tot zowel het EVRM als het IVRK. In de kern gaat het om het recht tot toegang tot de rechter. Voor de minderjarige patiënt gaat het erom zijn of haar recht te halen bij niet-nakoming van de geneeskundige behandelingsovereenkomst. Terecht pleit Liefaard voor het erkennen van Access to Fustice als een recht van het kind. ${ }^{41}$ Zowel uit de uitspraken van het VN-Kinderrechtencomité, het EHRM alsook de Raad van Europa blijkt dat lidstaten moeten beschikken over een effectief rechtsmiddel om eventuele inbreuken op rechten van het kind te kunnen herstellen. ${ }^{42}$ In de Guidelines on Child-friendly Fustice wordt niet voor niets gesteld dat er een balans dient te worden gevonden tussen het recht op toegang tot de rechter, het recht op effectieve participatie en de bescherming van minderjarigen, waarbij het VN-Kinderrechtencomité ook nog eens benadrukt dat kinderen in staat dienen te worden gesteld om hun rechten zoveel mogelijk zelf, eventueel met passende begeleiding, uit te kunnen oefenen over-

38. Tuchtcolleges voor de Gezondheidszorg, 'Ik heb een klacht', www.tuchtcollege-gezondheidszorg.nl/ik-heb-een-klacht.

39. Art. 65 lid 1 Wet BIG; Tuchtcolleges voor de Gezondheidszorg, 'Klachten over uw zorg?', Den Haag: Xerox/OBT, p. 4.

40. Zie bijv. CTG 1 oktober 2013, ECLI:NL:TGZCTG:2013:114. De tuchtrechter betrekt in zijn oordeel de vraag in hoeverre de minderjarige wilsonbekwaam is; D.P Engberts, T.A.M. van den Ende, L.E. KalkmanBogerd \& J.J.M. Linders, Gezondheidsrecht Tekst \& Commentaar, Den Haag: Kluwer 2019, achtste druk, artikel 65 Wet BIG

41. T. Liefaard, 'Access to Justice for Children: Towards a Specific Research and Implementation Agenda', The International Journal of Children's Rights, 2019, p. 105-227

42. UN Committee on the Rights of the Child, General comment No. 5 (2003): General measures of implementation of the Convention on the Rights of the Child (arts. 4, 42 and 44, para. 6), 27 November 2005 , CRC/GC/2003/5, par. 24; European Court of Human Rights, Guide on Article 6 of the Convention - Right to a fair trial (civil limb), 31 August 2019, par. 91; ECtHR 4 December 1995, Application no. 23805/94, par. 36-38 (Bellet v. France). eenkomstig hun evolving capacities. ${ }^{43}$ Nergens wordt uitgesloten dat minderjarigen recht hebben op een zelfstandige rechtsingang. Maar uit hetgeen hiervoor beschreven is, blijkt dat er nog wat haken en ogen zitten aan de invulling die hieraan is gegeven. In Nederland is, zo blijkt uit bovenstaande analyse, de toegang tot de rechter voor minderjarigen van 12 tot 16 jaar onvoldoende geborgd in geval zij een geneeskundige behandeling ondergaan waarvoor de ouders geen toestemming hebben gegeven en zij in geval van niet-nakoming van die behandelingsovereenkomst niet op één lijn liggen met de ouders. In een conflictsituatie tussen de ouders en het kind kan er weliswaar op grond van artikel 1:250 BW een bijzondere curator aan het kind worden toegewezen die de belangen van het kind in de procedure behartigt, maar dan nog beschikt de minderjarige niet, zoals dat wel het geval is bij de uitoefening van het toestemmingsrecht, over dezelfde rechtspositie als de ouders in de gerechtelijke procedure of als die van de 16- en 17-jarige patiënt. Zij kunnen in de in dit artikel beschreven situatie de gerechtelijke procedure niet zelf starten, aangezien zij processueel onbekwaam zijn.

In dit licht, maar ook in het licht van de toenemende maatschappelijke erkenning van minderjarigen als zelfstandige rechtssubjecten en de ontwikkelingen op het gebied van patient-centered care en shared-decision making valt er veel voor te zeggen de discrepantie tussen de materiële bekwaamheid en processuele onbekwaamheid voor 12- tot 16-jarigen op te heffen. In de context van de geneeskundige behandelingsovereenkomst zijn zij immers in staat tot een redelijke waardering van de eigen belangen ter zake. ${ }^{44}$ De daadwerkelijke grondslag voor het toekennen van (processuele) rechten is daarmee dus niet gelegen in de leeftijd van minderjarigen, maar in hun bekwaamheid.

Een oplossing voor de discrepantie tussen de materiële bekwaamheid en de processuele onbekwaamheid van 12tot 16 -jarigen in die specifieke situatie waarin zij een geneeskundige behandeling ondergaan zonder toestemming daarvoor van de ouders, is het toevoegen van een wettelijke bepaling in de WGBO waarin de processuele bekwaamheid voor minderjarigen die ook zelfstandig het toestemmingsrecht uitoefenen wordt geregeld. Op basis van zo'n regeling worden zij in staat gesteld om in op die geneeskundige behandelingsovereenkomst betrekking hebbende aangelegenheden in en buiten rechte op te treden.

Het verdient aanbeveling om dan tevens de verplichte bijstand door een jeugdadvocaat voor deze minderjarigen te regelen. Enerzijds om de rechtspositie van het kind binnen de procedure te verstevigen en anderzijds ook om in conflictsituaties tussen de ouders en het kind

43. Committee of Ministers of the Council of Europe, Guidelines on Childfriendly justice, Explanatory memorandum, 17 November 2010, par. 21, 25 and 32; art. 5 en 12 IVRK; M. Blaak, M. Bruning, M. Eigenraam, M. Kaandorp \& S. Meuwese, Handboek Internationaal Jeugdrecht, Leiden: Defence for Children 2012, p. 33; UN Committee on the Rights of the Child, General comment No. 12 (2009): The right of the child to be heard, 20 July 2009, CRC/C/GC/12, par. 84

44. Kamerstukken I/ 1989/90, 21561, nr. 3, p. 19-21. 
mogelijk tot 'common ground' te komen, alvorens de procedure inzake de niet-nakoming van de geneeskundige behandelingsovereenkomst voort te zetten. Minderjarigen die zelfstandig het toestemmingsrecht uitoefenen, kriigen zo een eigen formele rechtsingang, een eigen Access to Fustice. 